\title{
White-matter hyperintensities in first-episode psychosis
}

Marcus V. Zanetti, Maristela S. Schaufelberger, Cláudio C. de Castro, Paulo R. Menezes, Márcia Scazufca, Philip K. McGuire, Robin M. Murray and Geraldo F. Busatto

\section{Background}

White-matter hyperintensities have been associated with both schizophrenia and mood disorders, particularly bipolar disorder, but results are inconsistent across studies.

\section{Aims \\ To examine whether white-matter hyperintensities are a vulnerability marker for psychosis or are specifically associated with bipolar disorder.}

\section{Method}

$\mathrm{T}_{2}$-weighted magnetic resonance imaging data were acquired in 129 individuals with first-episode psychosis (either affective or non-affective psychoses) and 102 controls who were randomly selected from the same geographical areas. Visual white-matter hyperintensity ratings were used for group and subgroup comparisons.

\section{Results}

There were no statistically significant between-group differences in white-matter hyperintensity frequency or severity scores. No significant correlations were found between white-matter hyperintensity scores and duration of illness, duration of untreated psychosis, or severity of psychotic, manic or depressive symptoms.

\section{Conclusions}

White-matter hyperintensities are not associated with vulnerability to psychosis in general, or specifically with affective psychoses. Further, first-episode psychosis investigations using more quantitative methods are warranted to confirm these findings.

\section{Declaration of interest}

None. Funding detailed in Acknowledgements.
Increased rates of white-matter hyperintensities have been a frequent finding in magnetic resonance imaging (MRI) studies evaluating individuals with bipolar disorder compared with healthy controls. ${ }^{1}$ Such findings have been reported in individuals with the early stages of bipolar disorder as well as in their unaffected relatives, and this has been taken as suggestive that white-matter hyperintensities could reflect abnormal neurodevelopmental processes in bipolar disorder (see Hajek et $a l^{1}$ for review). White-matter hyperintensities have also been associated with unipolar depression, particularly in late-onset cases. ${ }^{2}$ However, other MRI studies of mood disorders have reported negative results. ${ }^{3}$ Moreover, there have been conflicting findings regarding the frequency of white-matter hyperintensities in schizophrenia. ${ }^{4}$ Most studies of white-matter hyperintensities have been conducted with small and heterogeneous samples and this might account for the above inconsistencies. We have evaluated the presence of white-matter hyperintensities in a large sample of people with first-episode psychosis, including individuals with non-affective and affective psychoses, and compared them with people who were psychosis-free and from the same geographical areas. We sought to determine whether white-matter hyperintensities can be linked to affective or psychotic symptoms in general, or whether they would be specifically associated with bipolar disorder.

\section{Method}

\section{Participants and assessment schedules}

The cases for the present study were selected from a sample of 200 individuals with first-episode psychosis who took part in a population-based case-control study investigating the incidence and risk factors for psychotic disorders in São Paulo, Brazil (see Menezes et $a l^{5}$ and Schaufelberger et $a l^{6}$ ). Inclusion criteria for people with first-episode psychosis in the neuroimaging arm of the study were: (a) current age between 18 and 50 years

(b) residence for 6 months or more in defined geographic areas of São Paulo

(c) diagnosis of a functional psychosis according to the DSM-IV ${ }^{7}$ (295-298, psychotic codes), as assessed by the Structured Clinical Interview for DSM-IV (SCID). ${ }^{8}$

Cases with psychotic disorders due to a general medical condition or substance-induced psychosis were excluded.

In order to obtain a population-based psychosis-free sample of controls, 102 next-door neighbours matched for age (within 5 years) and gender were also studied. They were screened to exclude the presence of psychotic symptoms using the Psychosis Screening Questionnaire, ${ }^{9}$ and interviewed with the SCID for the assessment of other psychiatric disorders. Exclusion criteria were the same as those for the psychosis group.

Other exclusion criteria for both groups were:

(a) history of head injury with loss of consciousness

(b) presence of neurological disorders or any organic disorders that could affect the central nervous system

(c) moderate or severe mental retardation

(d) contraindications for MRI scanning.

From the 200 people with first-episode psychosis included in the epidemiological investigation, ${ }^{5} 46$ did not meet the inclusion criteria for the neuroimaging part of the study. From the remaining eligible 154 individuals, 15 could not be contacted after their initial clinical assessment, 24 refused to take part in the MRI session, 2 were excluded due to movement-related imaging artefacts at MRI scanning, and 1 could not be included as he was identified by the epidemiological team when the MRI study and assessment of white-matter hyperintensities had already been concluded. There were no significant differences between the group of individuals with first-episode psychosis recruited from the epidemiological sample $(n=112)$ and the individuals that were 
lost $(n=42)$ with regard to: current age $(t$-test $=-0.99$, d.f. $=152$, $P=0.324)$, gender $\left(\chi^{2}=0.91\right.$, d.f. $\left.=1, P=0.339\right)$, number of years of education $(t$-test $=0.34$, d.f. $=152, P=0.760)$, monthly income per capita (Mann-Whitney test, $P=0.219$ ), employment status $\left(\chi^{2}=0.13\right.$, d.f. $\left.=1, P=0.715\right)$ and marital status $\left(\chi^{2}=0.54\right.$, d.f. $=1$, $P=0.463)$.

Seventeen additional people with first-episode psychosis living outside the catchment area of the incidence investigation were also studied, resulting in a total sample of 129 individuals with firstepisode psychosis.

Individuals with psychosis and controls were screened for substance use with the Alcohol Use Disorders Identification Test (AUDIT) $)^{10}$ and the South Westminster Questionnaire; ${ }^{11}$ diagnoses of substance abuse or dependence were assessed using the SCID. ${ }^{8}$ Handedness was assessed with Annett's Hand Preference Questionnaire. ${ }^{12}$ Medical history, including data on cerebrovascular risk factors (presence of arterial hypertension or diabetes) and information about antipsychotic drug treatment were obtained from case notes and interviews with individuals and/or family members.

Current psychotic symptom severity was assessed with the Positive and Negative Syndrome Scale (PANSS) ${ }^{13}$ on the day of MRI scanning. For the people with affective psychoses (bipolar disorder or unipolar major depression), current depressive and manic symptoms were also assessed using, respectively, the 31item Hamilton Rating Scale for Depression (HRSD) $)^{14}$ and the Young Mania Rating Scale (YMRS). ${ }^{15}$

There were 64 people who fulfilled $\mathrm{DSM}^{-\mathrm{IV}^{7}}$ diagnostic criteria for schizophrenia or schizophreniform disorder, 53 who fulfilled criteria for affective psychosis ( 25 cases with bipolar disorder and 28 with unipolar major depression) and 12 diagnosed under other psychosis categories, including schizoaffective disorder $(n=4)$, brief psychosis $(n=7)$ and psychotic disorder not otherwise specified $(n=1)$. Due to the small number of individuals in the latter categories, they were included only in the white-matter hyperintensity comparisons between the overall psychosis group and controls, but not in comparisons across diagnostic subgroups. Mood symptom ratings (HRSD and YMRS) were not available for 10 people in the affective psychoses subgroups (4 with bipolar disorder and 6 with unipolar major depression), as these were investigated at the outset of the study when those instruments had not yet been incorporated into our clinical battery.

In the schizophrenia/schizophreniform disorder subgroup, 18 individuals $(28 \%)$ were not using psychotropic medication at the time of MRI scanning; 42 (45\%) were taking antipsychotic drugs (66\% typical and 33\% atypical), 8 (12\%) received antidepressant agents, and $6(9 \%)$ were taking mood stabilisers. There were 6 individuals with bipolar disorders $(24 \%)$ who were not using psychotropic medication; $12(48 \%)$ were taking antipsychotics (75\% typical and 25\% atypical), 13 (52\%) mood stabilisers and $2(8 \%)$ antidepressant agents. Of the individuals with unipolar major depression 7 (25\%) were not taking psychotropic medication; $16(57 \%)$ were using antipsychotic drugs (50\% typical and 50\% atypical), $14(50 \%)$ antidepressant agents and $4(14 \%)$ mood stabilisers. From the 12 people that received other diagnoses (4 schizoaffective disorder, 7 brief psychosis and 1 psychotic disorder not otherwise specified), 6 were not on psychotropic medication, 6 were receiving antipsychotic medications and 4 mood stabilisers.

The study was approved by local ethics committees and all participants gave informed written consent.

\section{Brain Imaging}

Magnetic resonance imaging data were acquired using two identical 1.5 T GE Signa systems (General Electric, Milwaukee,
Wisconsin, USA). Exactly the same protocol was used, including acquisition of transaxial $\mathrm{T}_{2}$-weighted fast spin-echo images repetition time $(\mathrm{TR})=4000 \mathrm{~ms}$, echo time $(\mathrm{TE})=80 \mathrm{~ms}$, field of view $(F O V)=24 \mathrm{~cm}$, slice thickness $=3 \mathrm{~mm}$, no gap between the slices, matrix size $=256 \times 256$ ) for the assessment of white-matter hyperintensities.

Visual analyses of white-matter hyperintensities were performed by an expert neuroradiologist masked to diagnosis (C.C.C) using the Scheltens scale. ${ }^{16}$ This scale affords prevalence estimates, as well as semi-quantitative ratings based on the number and size of hyperintense lesions, thus providing indirect estimates of severity. Scores for white-matter hyperintensities in periventricular regions (frontal caps, band hyperintensities, and occipital caps) range from zero (absent) to one (hyperintensities up to $5 \mathrm{~mm}$ ) and two (from 6 to $10 \mathrm{~mm}$ ); in other brain regions (deep subcortical frontal, parietal, temporal and occipital areas; basal ganglia and infratentorial regions), scores range from zero (absent) to one (up to $3 \mathrm{~mm}$ and a maximum of 5 lesions), two ( 6 or more lesions up to $3 \mathrm{~mm}$ ), three (up to 5 lesions of 4 to $10 \mathrm{~mm}$ ), four (6 or more lesions of 4 to $10 \mathrm{~mm}$ ), five (at least one lesion of more than $10 \mathrm{~mm}$ ) and six (confluent lesions).

Fifty images were randomly selected and rated again for the location and severity of white-matter hyperintensities by another expert neuroradiologist, in order to provide data for interrater reliability calculations. The intraclass correlation coefficient was employed, and total agreement between raters was found for the following Scheltens scale variables: band hyperintensities, occipital periventricular, deep temporal and occipital white-matter hyperintensities, and all basal ganglia and infratentorial regions but globus pallidus. The other intraclass correlation coefficient measures obtained were: frontal periventricular, 0.91; deep frontal, 0.92; deep parietal, 0.81; and globus pallidus, 0.96 .

\section{Statistical analyses}

Group comparisons of demographic and clinical data were computed using analysis of variance (ANOVA) for continuous variables or $\chi^{2}$-test for categorical variables.

The following three comparisons of the proportion of people presenting with white-matter hyperintensities (total scores, as well as separate rates in different brain regions) were carried out using $\chi^{2}$-tests: overall psychosis group $(n=129) v$. controls $(n=102)$; affective psychosis subgroup ( $n=53$, including both those with bipolar disorder and those with unipolar depression with psychotic features) v. non-affective psychosis subgroup ( $n=64$, including schizophrenia/schizophreniform disorder) v. control group ( $n=102)$; and schizophrenia/schizophreniform disorder $(n=64)$, psychotic bipolar disorder $(n=25)$ and unipolar psychotic depression $(n=28)$ subgroups $v$. controls. In addition, as the Scheltens scale provides semi-quantitative ratings, we also conducted comparisons of white-matter hyperintensity scores using Kruskal-Wallis tests, in order to investigate the existence of, respectively, group and subgroup differences in severity.

Finally, Spearman coefficients were used in order to assess the presence of significant correlations between severity ratings and clinical measures, including duration of illness, duration of untreated psychosis (defined as the duration of time from the onset of psychotic symptoms up to the beginning of antipsychotic medication intake), duration of exposure to antipsychotic medication, and severity scores on the positive and negative PANSS scores (for the overall psychosis group), the YMRS (for the bipolar disorder subgroup) and the HRSD (for the unipolar depression subgroup). Due to the large number of correlation indices calculated, levels of significance were set at $P<0.05$ corrected for multiple comparisons using Bonferroni's method. 


\begin{tabular}{|c|c|c|c|c|c|c|}
\hline & $\begin{array}{c}\text { Overall } \\
\text { psychosis } \\
(n=129)\end{array}$ & $\begin{array}{c}\text { Affective } \\
\text { psychosis } \\
(n=53)\end{array}$ & $\begin{array}{l}\text { Schizophrenia and } \\
\text { related psychosis } \\
\qquad(n=64)\end{array}$ & $\begin{array}{l}\text { Bipolar } \\
\text { disorder } \\
(n=25)\end{array}$ & $\begin{array}{c}\text { Unipolar } \\
\text { depression } \\
(n=28)\end{array}$ & $\begin{array}{l}\text { Controls } \\
(n=102)\end{array}$ \\
\hline Mean age, years (range) & $29.0(18-50)$ & $29.6(18-49)$ & $28.0(18-50)$ & $28.7(18-47)$ & $30.5(20-49)$ & $30.4(18-50)$ \\
\hline Male, $n(\%)$ & $71(55.0)$ & $19(35.8)$ & $46(71.9)$ & $10(40.0)$ & $9(32.1)$ & $54(54.1)$ \\
\hline Education, years: mean (s.d.) & $8.4(4.06)$ & $8.7(4.2)$ & $8.7(3.7)$ & $8.5(4.2)$ & $8.9(4.2)$ & $10.1(4.1)$ \\
\hline Disease duration, weeks: mean (s.d.) & $39.8(49.9)$ & $30.8(24.6)$ & $49.6(63.6)$ & $27.1(19.27)$ & $34.1(28.5)$ & - \\
\hline $\begin{array}{l}\text { Duration of untreated psychosis, } \\
\text { weeks: mean (s.d.) }\end{array}$ & $22.8(47.8)$ & $8.11(12.3)$ & 35.9 (63.6) & $5.9(7.0)$ & $10.0(15.5)$ & - \\
\hline \multicolumn{7}{|l|}{ Substance abuse or dependence, $n(\%)$} \\
\hline No & $96(74.4)$ & $42(79.2)$ & $44(68.8)$ & $20(80.0)$ & $22(78.6)$ & $96(94.1)$ \\
\hline Yes & $33(25.6)$ & $11(20.8)$ & 20(31.3) & $5(20.0)$ & $6(21.4)$ & $6(5.9)$ \\
\hline \multicolumn{7}{|l|}{ Vascular risk factors, $n(\%)$} \\
\hline No & $122(94.6)$ & $49(92.5)$ & $62(96.9)$ & $23(92.0)$ & $26(92.9)$ & $96(94.4)$ \\
\hline Arterial hypertension & $4(3.1)$ & $3(5.7)$ & $1(1.6)$ & $2(8.0)$ & $1(3.6)$ & $5(4.9)$ \\
\hline Diabetes mellitus & $1(0.8)$ & $0(0)$ & $0(0)$ & $0(0)$ & $0(0)$ & $1(1.0)$ \\
\hline Both & $2(1.6)$ & $1(1.9)$ & $1(1.6)$ & $0(0)$ & $1(3.6)$ & $0(0)$ \\
\hline
\end{tabular}

\section{Results}

\section{Demographic and clinical details}

Demographic and clinical data for the psychosis and control groups are summarised in Table 1. Groups (psychosis and controls) and subgroups (affective $v$. non-affective psychosis $v$. controls, and schizophrenia/schizophreniform psychosis $v$. bipolar disorder $v$. unipolar major depression $v$. controls) did not differ with regard to mean age, years of education, handedness and presence of vascular risk factors (arterial hypertension and diabetes). There were significantly more males than females in the schizophrenia/schizophreniform psychosis subgroup relative to controls and to all other diagnostic subgroups $\left(\chi^{2}\right.$ ranging from 5.32 to 15.24 , d.f. $=1$, all $P<0.023$ ). The control group also had significantly more males than females relative both to the overall affective psychosis subgroup $\left(\chi^{2}=4.56\right.$, d.f. $\left.=1, P=0.042\right)$ and to the unipolar depression subgroup $\left(\chi^{2}=4.17\right.$, d.f. $\left.=1, P=0.055\right)$.

The psychosis group as a whole showed more comorbid substance abuse or dependence in comparison with the control group $\left(\chi^{2}=15.75\right.$, d.f. $\left.=1, P<0.001\right)$. Also, there were significantly more people with comorbid diagnoses of substance abuse or dependence in all three diagnostic subgroups (affective psychosis, schizophrenia/schizophreniform psychosis, bipolar disorder and unipolar depression) relative to controls $\left(\chi^{2}\right.$ ranging from 5.06 to 19.16 , d.f. $=1$, all $P<0.040)$. No significant differences with regard to comorbid substance abuse or dependence were observed between diagnostic subgroups in paired comparisons ( $\chi^{2}$ ranging from 0.01 to 1.64 , d.f. $=1$, all $P>0.215$ ).

\section{Frequency and severity}

The frequencies of white-matter hyperintensities in each group and subgroup are shown in Table 2. Apart from the rates in deep frontal and parietal regions, scores for all other specific brain regions were very modest or null (Table 2). Therefore, we proceeded with the subsequent statistical analyses only for total white-matter hyperintensity ratings, and for subscores in deep frontal and deep parietal regions (Table 3).

Using those ratings, no differences in prevalence were observed between: the psychosis group as a whole $v$. controls; individuals with affective $v$. non-affective psychoses; or the subgroups with bipolar disorder, unipolar depression and schizophrenia/ schizophreniform psychosis $v$. controls.

Comparisons of scores using Kruskal-Wallis tests revealed no between-group or subgroups severity differences in either of the variables evaluated (online Table DS1). Results remained negative when we repeated such analyses after excluding those people with a positive diagnosis of substance abuse or dependence (20 with schizophrenia/schizophreniform, 5 with bipolar disorder, 6 with psychotic depression and 6 in the control group).

Table 2 Frequencies of white-matter hyperintensities across separate psychosis subgroups and healthy controls

\begin{tabular}{|c|c|c|c|c|c|c|}
\hline & $\begin{array}{c}\text { Overall } \\
\text { psychosis group } \\
n=129 \\
n(\%)\end{array}$ & $\begin{array}{c}\text { Affective } \\
\text { psychoses } \\
n=53 \\
n(\%)\end{array}$ & $\begin{array}{l}\text { Schizophrenia/ } \\
\text { schizophreniform psychosis } \\
\qquad \begin{array}{c}n=64 \\
n(\%)\end{array}\end{array}$ & $\begin{array}{c}\text { Bipolar } \\
\text { disorder } \\
n=25 \\
n(\%)\end{array}$ & $\begin{array}{c}\text { Unipolar } \\
\text { depression } \\
n=28 \\
n(\%)\end{array}$ & $\begin{array}{c}\text { Controls } \\
n=102 \\
n(\%)\end{array}$ \\
\hline Total white-matter hyperintensities & $32(24.8)$ & $12(22.6)$ & $18(28.1)$ & $7(28.0)$ & $5(17.9)$ & $30(29.4)$ \\
\hline \multicolumn{7}{|c|}{ Periventricular white-matter hyperintensities } \\
\hline Total & $2(1.6)$ & $1(1.9)$ & $1(1.6)$ & $1(4.0)$ & $0(0.0)$ & $6(5.9)$ \\
\hline Frontal & $2(1.6)$ & $1(1.9)$ & $1(1.6)$ & $1(4.0)$ & $0(0.0)$ & $6(5.9)$ \\
\hline Bands & $0(0.0)$ & $0(0.0)$ & $0(0.0)$ & $0(0.0)$ & $0(0.0)$ & $2(2)$ \\
\hline Occipital & $1(0.8)$ & $1(1.9)$ & $0(0.0)$ & $1(4.0)$ & $0(0.0)$ & $1(0.4)$ \\
\hline \multicolumn{7}{|l|}{ Deep white-matter hyperintensities } \\
\hline Total & $32(24.8)$ & $12(22.6)$ & $18(28.1)$ & $7(28.0)$ & $5(17.9)$ & $26(25.5)$ \\
\hline Frontal & $29(22.5)$ & $12(22.6)$ & $15(23.4)$ & 7 (28.0) & 5 (17.9) & $21(20.6)$ \\
\hline Parietal & $14(10.9)$ & $6(11.3)$ & 7 (10.9) & $4(16)$ & $2(7.1)$ & $15(14.7)$ \\
\hline Temporal & $1(0.8)$ & $0(0.0)$ & $1(1.6)$ & $0(0.0)$ & $0(0.0)$ & $0(0.0)$ \\
\hline Occipital & $1(0.8)$ & $0(0.0)$ & $1(1.6)$ & $0(0.0)$ & $0(0.0)$ & $1(1.0)$ \\
\hline
\end{tabular}


Table 3 Statistical analysis of white-matter hyperintensities across separate pyschosis subgroups and health controls

\begin{tabular}{|c|c|c|c|c|c|c|c|c|c|}
\hline & \multicolumn{9}{|c|}{ Comparisons } \\
\hline & \multicolumn{3}{|c|}{ Overall psychosis v. controls } & \multicolumn{3}{|c|}{ Affective $v$. non-affective $v$. controls } & \multicolumn{3}{|c|}{ Diagnostic subgroups ${ }^{a}$} \\
\hline & $\chi^{2}$ & d.f. & $P$ & $\chi^{2}$ & d.f. & $P$ & $\chi^{2}$ & d.f. & $P$ \\
\hline Total white-matter hyperintensities & 0.61 & 1 & 0.457 & 0.83 & 2 & 0.778 & 1.51 & 3 & 0.680 \\
\hline \multicolumn{10}{|l|}{ Deep white-matter hyperintensities } \\
\hline Total & 0.01 & 1 & 1.000 & 0.46 & 2 & 0.795 & 1.17 & 3 & 0.796 \\
\hline Frontal & 0.12 & 1 & 0.750 & 0.21 & 2 & 0.901 & 1.00 & 3 & 0.801 \\
\hline Parietal & 0.77 & 1 & 0.427 & 0.63 & 2 & 0.728 & 1.56 & 3 & 0.667 \\
\hline
\end{tabular}

In the entire sample, there were no significant gender differences either in terms of prevalence $\left(\chi^{2}\right.$ ranging from 0.01 to 1.97, d.f. $=1$, all $P>0.173$ ) or severity (Kruskal-Wallis tests, all $P>0.208)$. There were neither significant differences in prevalence or severity (white-matter hyperintensities: total, total in periventricular regions, total deep, and deep frontal or deep parietal) between people who had a diagnosis of substance abuse or dependence and those who did not $\left(\chi^{2}\right.$ ranging from 0.11 to 2.90, d.f. $=1$, all $P>0.105$; Kruskal-Wallis tests, all $P>0.086$ ).

\section{Correlations between scores and clinical variables}

No significant correlations were found between white-matter hyperintensity scores and duration of illness, duration of untreated psychosis, duration of exposure to antipsychotic medication or severity of psychotic symptoms - total, positive or negative symptoms (as measured with the PANSS) - in the overall psychosis group (all correlations with associated $P \geqslant 0.400$, corrected for multiple comparisons).

In the bipolar disorder subgroup, there were no significant correlations between the severity of white-matter hyperintensities and the intensity of manic symptoms, as measured by the YMRS (all $P=0.068$, corrected). Also, no significant correlations were observed between white-matter hyperintensity ratings and HRSD scores in the unipolar depression subgroup (all $P=1.00$, corrected).

\section{Discussion}

\section{The psychosis group and comparisons between affective and non-affective psychoses}

The present study is, to our knowledge, the first to systematically evaluate the presence, severity and topography of white-matter hyperintensities in a large group of people with first-episode psychosis compared with healthy controls, using an epidemiological design for the recruitment of the participants. Earlier qualitative investigations cited the possible occurrence of white matter lesions in association with first-episode psychosis (as reviewed by Lawrie et al), ${ }^{17}$ whereas two recent studies ${ }^{18,19}$ evaluated the frequency of incidental radiological findings, including white-matter hyperintensities, in individuals with first-episode psychosis through visual non-systematised inspection, with conflicting results.

In the present study, no differences between the overall psychosis group and controls were found in terms of prevalence or severity of these lesions, independently of their brain location. Similarly, no statistically significant differences in the frequencies and severity scores were identified when comparing the affective psychosis (psychotic bipolar disorder and unipolar depression), non-affective psychosis (schizophrenia/schizophreniform disorder) and control subgroups. These results suggest that the presence and extension of white-matter hyperintensities are not associated with vulnerability to psychotic symptoms in adult populations. The absence of significant correlations between white-matter hyperintensity scores and clinical variables related to psychotic features - duration of illness, duration of untreated psychosis and severity of psychotic symptomatology - corroborates this conclusion. It is important, however, to raise the possibility that white-matter hyperintensities could be a feature related to illness chronicity, and this might explain why there were no group differences in our investigation of participants in the early course of their illness. Future longitudinal MRI studies would be needed to elucidate this issue.

\section{Unipolar depression, schizophrenia/schizophreniform psychosis and bipolar disorder}

There were no significantly increased rates or severity indices of white-matter hyperintensities in any of the three separate psychosis subgroups relative to the control group.

Our negative findings in the unipolar depression subgroup are in accordance with the most recent MRI studies carried out with samples of non-elderly adults with major depression. ${ }^{3,20}$ Also, most studies that evaluated the presence of white-matter hyperintensities in schizophrenia have reported negative results, ${ }^{21,22}$ although the literature is conflicting. ${ }^{4}$

Finally, with regard to the bipolar disorder subgroup, the low prevalence of white-matter hyperintensities, indistinguishable from that of the other subgroups, suggests that the magnitude of any supposed white-matter hyperintensity increments in association with bipolar disorder is not sufficiently large to be detected with a sample of the size recruited for the present study, and with the use of a control group selected from the same geographical region. Findings of increased rates in bipolar disorder have been previously reported: two meta-analyses have found that the risk of individuals with bipolar disorder presenting with white-matter hyperintensities is over three times higher than that for healthy controls. $^{23,24}$ In spite of that, several studies have reported negative findings. ${ }^{3,21,22,25}$ Strakowski et $a{ }^{26}$ in the only study to date that evaluated frequency in first-episode mania, failed to find a significant difference in comparison with controls, despite reporting a 1.7 higher (non significant) rate of subcortical whitematter hyperintensities in the bipolar disorder group. Moreover, there is considerable heterogeneity in previous reports regarding the prevalence rates in both those with bipolar disorder and control samples, with frequencies of total hyperintensities ranging, respectively, from approximately $5 \%$ to $66 \%$ and $0 \%$ to $58 \%$ among studies that evaluated young or adult individuals. ${ }^{3,22,24,25,27,28}$

The main location where these lesions are found is also controversial, with some studies reporting increased rates of white-matter hyperintensities in periventricular regions in bipolar disorder samples, ${ }^{23}$ while others highlight findings of increased deep white-matter hyperintensity ratings associated with bipolar disorder. ${ }^{24,27-29}$ The only quantitative analysis of white matter lesions in people with psychiatric disorders published to date 
reported increased volumes of white-matter hyperintensity in anterior brain regions of individuals with bipolar disorder compared with either those with unipolar depression or healthy controls $^{30}$. Although several papers reported frontal ${ }^{27,31}$ and frontoparietal ${ }^{32,33}$ location of white-matter lesions in association with bipolar disorder, only one recent study ${ }^{34}$ directly compared frontal deep white-matter hyperintensities between participants with bipolar disorder and controls, in an elderly population, and found increased left frontal scores in the bipolar disorder group. Few authors have systematically assessed vascular risk factors and history of substance abuse or dependence in the participants enrolled, and most studies have been conducted with small and heterogeneous samples, poorly controlled for clinical disease course, age, gender and comorbidities. All these factors, together with methodological differences among studies, are likely to have contributed to the lack of consistency in the findings.

Recent MRI studies using diffusion tensor imaging in people with bipolar disorder, ${ }^{35,36}$ although as yet scarce and involving modest samples, have revealed structural white matter abnormalities - located in the frontal lobe and adjacently to the striatum and thalamus. Such findings suggest that diffusion tensor imaging techniques may be more sensitive to detect white matter abnormalities in association with bipolar disorder. In support of this possibility, a study combining diffusion tensor imaging and white-matter hyperintensity measurements in healthy elderly individuals detected structural damage evidenced by increased diffusion coefficients (as measured by diffusion tensor imaging) in areas of normally appearing white matter surrounding foci of white-matter hyperintensities. ${ }^{37}$ Although the latter evidence has been found in an elderly population, in which different mechanisms may be involved in the emergence of white-matter hyperintensities, it is possible that they might simply represent the 'tip of the iceberg' in terms of structural white matter lesions. Thus, the presence and severity of white-matter hyperintensities associated with bipolar disorder might be understood as an extreme consequence of underlying microstructural processes that affect brain connectivity and which may be more specifically investigated using diffusion tensor imaging methods.

It is possible that some significant findings of our study could have been obscured by factors unrelated to psychiatric diagnoses. For instance, rates of white-matter hyperintensities in the general population are known to increase in direct proportion to the presence of cardiovascular risk factors, particularly in elderly people. ${ }^{38}$ However, we studied a young adult sample with a low prevalence of cerebrovascular risk factors (Table 1). Besides that, no differences in the rates of arterial hypertension and diabetes were observed between people with psychosis and those without, or across the separate diagnostic subgroups. Therefore, we believe that our results are not attributable to group differences in risk factors for cerebrovascular disease. One might also question whether the use of psychotropic medication could influence the presence of white matter lesions. However, there is no evidence that the use of lithium, tricyclic antidepressants or antiepileptic drugs would be linked to increased rates of white-matter hyperintensities. ${ }^{3,4,23,24}$ Data regarding the possible influence of antipsychotic drugs is scarce, but we studied individuals whose psychotic disorders were at an early stage and, therefore, with a short history of exposure to antipsychotic medication. Thus, the probability of any biases due to exposure to such drugs in our study is low.

\section{Limitations}

A number of methodological limitations should be highlighted. First, all our participants with bipolar disorder and major depressive disorder presented with psychotic symptoms, and one could argue that these individuals do not adequately represent the whole population suffering from affective disorders. Second, as we employed a semi-quantitative visual analysis method, we cannot discount the possibility that subtler white matter abnormalities may not have been detected. Replication of our results in studies using more quantitative methods for white-matter hyperintensity assessment is, therefore, warranted. Finally, although we studied a sample of individuals with first-onset psychosis of greater size than previous studies, the size of each diagnostic subgroup may have been insufficiently large to avoid the risk of type II errors. Therefore, the findings reported herein should be extended using rating methods of greater sensitivity in larger subgroups.

\begin{abstract}
Marcus V. Zanetti, MD, Maristela S. Schaufelberger, MD, Laboratory of Psychiatric Neuroimaging, Institute and Department of Psychiatry, University of São Paulo; Cláudio C. de Castro, MD, PhD, Department of Radiology, University of São Paulo; Claudio C. de Castro, MD, PhD, Department of Radiology, University of São
Paulo; Paulo R. Menezes, MD, PhD, Department of Preventive Medicine, Faculty of Medicine, and Section of Epidemiology, University Hospital, University of São Paulo; Márcia Scazufca, PhD, Laboratory of Psychopathology and Psychiatric Therapeutics, Institute and Department of Psychiatry, University of São Paulo, São Paulo, Brazil; Philip K. McGuire, MD, PhD, Robin M. Murray, MD, PhD, Department of Psychological Medicine, Institute of Psychiatry, London, UK; Geraldo F. Busatto, MD, PhD, Laboratory of Psychiatric Neuroimaging, Institute and Department of Psychiatry, University of São Paulo, São Paulo, Brazil.
\end{abstract}

Correspondence: Marcus V. Zanetti,Centro de Medicina Nuclear, $3^{\circ}$ andar, LIM21, Rua Dr. Ovídio Pires de Campos, s/n, CEP 05403-010, São Paulo, Brazil. Email: marcus_zanetti@yahoo.com.br

First received 10 Apr 2007, final revision 29 Dec 2007, accepted 29 Feb 2008

\section{Acknowledgements}

We thank the Brazilian First-Contact Psychosis clinical team for the recruitment of the participants in the community. The authors also thank Leticia Coutinho for her invaluable support in the statistical analyses, Claudia C. Leite and Edson Amaro Jr. for their help in the collection of MRI data, and Zélia M. S. Campos for her contribution in rating the MRI scans for reliability calculations. This study was funded by the Wellcome Trust, UK. P.R.M. and M.S. are partly funded by the CNPq-Brazil.

\section{References}

1 Hajek T, Carrey N, Alda M. Neuroanatomical abnormalities as risk factors for bipolar disorder. Bipolar Disord 2005; 7: 393-403.

2 Soares JC, Mann JJ. The anatomy of mood disorders - review of structural neuroimaging studies. Biol Psychiatry 1997; 41: 86-106.

3 Sassi RB, Brambilla P, Nicoletti M, Mallinger AG, Frank E, Kupfer DJ, Keshavan MS, Soares JC. White matter hyperintensities in bipolar and unipolar patients with relatively mild-to-moderate illness severity. J Affect Disord 2003; 77: 237-45.

4 Persaud R, Russow H, Harvey I, Lewis SW, Ron M, Murray RM, du Boulay G. Focal signal hyperintensities in schizophrenia. Schizophr Res 1997; 27 55-64.

5 Menezes PR, Scafzufca M, Busatto GF, Coutinho LMS, McGuire PK, Murray RM. Incidence of first contact psychosis in São Paulo, Brazil. Br J Psychiatry 2007; 191 (suppl 51): s102-6.

6 Schaufelberger MS, Duran FLS, Lappin JM, Scazufca M, Amaro Jr A, Leite CC de Castro CC, Murray RM, McGuire PK, Menezes PR, Busatto GF. Grey matter abnormalities in Brazilians with first-episode psychosis. Br J Psychiatry 2007; 191 (suppl 51): 117-22.

7 American Psychiatry Association. Diagnostic and Statistical Manual of Mental Disorders (4th edn) (DSM-IV). APA, 1994.

8 First MB, Spitzer RL, Gibbon M, Williams JBW. Structured Clinical Interview for DSM-IV Axis I Disorders, Patient Edition (SCID-I/P). Biometrics Research, New York State Psychiatry Institute, 1995.

9 Bebbington PE, Nayani T. The Psychosis Screening Questionnaire. Int $J$ Methods Psychiatr Res 1995; 5: 11-9.

10 Saunders JB, Aasland OG, Babor TF, de la Fuente JR, Grant M. Development of the Alcohol Use Disorders Identification Test (AUDIT): WHO Collaborative Project on early detection of persons with harmful alcohol consumption - II. Addiction 1993; 88: 791-804. 
11 Menezes PR, Johnson S, Thornicroft G, Marshall J, Prosser D, Bebbington P Kuipers E. Drug and alcohol problems among individuals with severe mental illness in south London. Br J Psychiatry 1996; 168: 612-9.

12 Annett M. A classification of hand preference by association analysis. $\mathrm{Br} J$ Psychol 1970; 61: 303-21.

13 Kay SR, Fiszbein A, Opler LA. The positive and negative syndrome scale (PANSS) for schizophrenia. Schizophr Bull 1987; 13: 261-76.

14 Hamilton M. Rating scale for depression. J Neurol Neurosurg Psychiatry 1960 23: $56-62$.

15 Young RC, Biggs JT, Ziegler VE, Meyer DA. A rating scale for mania: reliability, validity and sensitivity. Br J Psychiatry 1978; 133: 429-35.

16 Scheltens $P$, Barkhof $F$, Leys D, Pruvo JP, Nauta JJ, Vermersch $P$, Steinling $M$, Valk J. A semiquantative rating scale for the assessment of signal hyperintensities on magnetic resonance imaging. J Neurol Sci 1993; 114 7-12.

17 Lawrie SM, Abukmeil SS, Chiswick A, Egan V, Santosh CG, Best JJ. Qualitative cerebral morphology in schizophrenia: a magnetic resonance imaging study and systematic literature review. Schizophr Res 1997; 25: 155-66.

18 Lubman DI, Velakoulis D, McGorry PD, Smith DJ, Brewer W, Stuart G, Desmond $\mathrm{P}$, Tress $\mathrm{B}$, Pantelis $\mathrm{C}$. Incidental radiological findings on brain magnetic resonance imaging in first-episode psychosis and chronic schizophrenia. Acta Psychiatr Scand 2002; 106: 331-6.

19 Borgwardt SJ, Radue EW, Götz K, Aston J, Drewe M, Gschwandtner U, Halle S, Pflüger M, Stieglitz RD, McGuire PK, Riecher-Rössler A. Radiological findings in individuals at high risk of psychosis. J Neurol Neurosurg Psychiatry 2006; 77: 229-33.

20 Iosifescu DV, Renshaw PF, Lyoo IK, Lee HK, Perlis RH, Papakostas GI Nierenberg AA, Fava M. Brain white-matter hyperintensities and treatment outcome in major depressive disorder. Br J Psychiatry 2006; 188: 180-5.

21 Brown FW, Lewine RJ, Hudgins PA, Risch SC. White matter hyperintensity signals in psychiatric and nonpsychiatric subjects. Am J Psychiatry 1992 149: $620-5$.

22 Krabbendam L, Honig A, Wiersma J, Vuurman EF, Hofman PA, Derix MM Nolen WA, Jolles J. Cognitive dysfunctions and white matter lesions in patients with bipolar disorder in remission. Acta Psychiatr Scand 2000; 101 274-80.

23 Altshuler LL, Curran JG, Hauser P, Mintz J, Denicoff K, Post R. T2 hyperintensities in bipolar disorder: magnetic resonance imaging comparison and literature meta-analysis. Am J Psychiatry 1995; 152: 1139-44.

24 Videbech P. MRI findings in patients with affective disorder: a meta-analysis. Acta Psychiatr Scand 1997; 96: 157-68.

25 Chang K, Barnea-Goraly N, Karchemskiy A, Simeonova DI, Barnes P, Ketter T, Reiss AL. Cortical magnetic resonance imaging findings in familial pediatric bipolar disorder. Biol Psychiatry 2005; 58: 197-203.
26 Strakowski SM, Woods BT, Tohen M, Wilson DR, Douglass AW, Stoll AL. MRI subcortical signal hyperintensities in mania at first hospitalization. Biol Psychiatry 1993; 33: 204-6.

27 Lyoo IK, Lee HK, Jung JH, Noam GG, Renshaw PF. White matter hyperintensities on magnetic resonance imaging of the brain in children with psychiatric disorders. Compr Psychiatry 2002; 43: 361-8.

28 Ahn KH, Lyoo IK, Lee HK, Song IC, Oh JS, Hwang J, Kwon J, Kim MJ, Kim M, Renshaw PF. White matter hyperintensities in subjects with bipolar disorder. Psychiatry Clin Neurosci 2004; 58: 516-21.

29 McDonald WM, Tupler LA, Marsteller FA, Figiel GS, Disouza S, Nemeroff CB, Krishnan KR. Hyperintense lesions on magnetic resonance images in bipolar disorder. Biol Psychiatry 1999; 45: 965-71.

30 Dupont RM, Jernigan TL, Heindel W, Butters N, Shafer K, Wilson T, Hesselink $\mathrm{J}$, Gillin JC. Magnetic resonance imaging and mood disorders. Localization of white matter and other subcortical abnormalities. Arch Gen Psychiatry 1995; 52: $747-55$

31 Dupont RM, Butters N, Schafer K, Wilson T, Hesselink J, Gillin JC. Diagnostic specificity of focal white matter abnormalities in bipolar and unipolar mood disorder. Biol Psychiatry 1995; 38: 482-6.

32 Figiel GS, Krishnan KR, Rao VP, Doraiswamy M, Ellinwood EH Jr, Nemeroff CB, Evans $D$, Boyko O. Subcortical hyperintensities on brain magnetic resonance imaging: a comparison of normal and bipolar subjects. J Neuropsychiatry Clin Neurosci 1991; 3: 18-22.

33 Aylward EH, Roberts-Twillie JV, Barta PE, Kumar AJ, Harris GJ, Geer M, Peyser $\mathrm{CE}$, Pearlson GD. Basal ganglia volumes and white matter hyperintensities in patients with bipolar disorder. Am J Psychiatry 1994; 151: 687-93.

34 de Asis JM, Greenwald BS, Alexopoulos GS, Kiosses DN, Ashtari M, Heo M, Young RC. Frontal signal hyperintensities in mania in old age. Am J Geriatr Psychiatry 2006; 14: 598-604.

35 Haznedar MM, Roversi F, Pallanti S, Baldini-Rossi N, Schnur DB, Licalzi EM Tang C, Hof PR, Hollander E, Buchsbaum MS. Fronto-thalamo-striatal gray and white matter volumes and anisotropy of their connections in bipolar spectrum illnesses. Biol Psychiatry 2005; 57: 733-42.

36 Beyer JL, Taylor WD, MacFall JR, Kuchibhatla M, Payne ME, Provenzale JM, Cassidy F, Krishnan KR. Cortical white matter microstructural abnormalities in bipolar disorder. Neuropsychopharmacology 2005; 30: 2225-9.

37 Firbank MJ, Minett T, O'Brien JT. Changes in DWI and MRS associated with white matter hyperintensities in elderly subjects. Neurology 2003; 61: 950-4.

38 Zanetti MV, Cordeiro Q, Busatto GF. Late onset bipolar disorder associated with white matter hyperintensities: a pathophysiological hypothesis. Prog Neuropsychopharmacol Biol Psychiatry 2007; 31: 551-6.

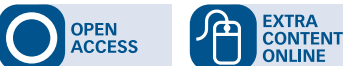

